\title{
The new integrated aeromagnetic map of the Phlegrean Fields volcano and surrounding areas
}

\author{
Valeria Paoletti $\left({ }^{1}\right)$, Maurizio Fedi $\left({ }^{1}\right)$, Giovanni Florio $\left({ }^{1}\right)$, Robert Supper $\left({ }^{2}\right)$ and Antonio Rapolla $\left({ }^{1}\right)$ \\ ( $\left.{ }^{1}\right)$ Dipartimento di Scienze della Terra, Università degli Studi di Napoli «Federico II», Napoli, Italy
}

${ }^{(2)}$ Geological Survey of Austria, Department of Geophysics, Vienna, Austria

\begin{abstract}
In this paper we present and analyze the new detailed aeromagnetic data set resulting from a recent survey carried out in the Phlegrean Fields volcanic area. The survey was aimed at gaining new insight into the volcanological characteristics of the region north of Phlegrean Fields (Parete-Villa Literno area) where remarkable thickness of volcanic/sub-volcanic rocks were found in wells. Measurement of total magnetic field was performed on two different flight levels, $70 \mathrm{~m}$ and $400 \mathrm{~m}$ above the ground surface, along flight lines spaced 400 $\mathrm{m}$ apart. Both aeromagnetic maps show the noisy effect of linear anomalies evidently due to the presence of railway lines. To filter out these local anomalies a method based on discrete wavelet transform was used, allowing an accurate local filtering and leaving the rest of the field practically unchanged. The filtered data set was integrated with the existing Agip aeromagnetic map of the Phlegrean Fields, leading to a new aeromagnetic map of the whole Phlegrean volcanic area. The compilation of the pole reduced map and of the maps of the Analytic Signal and of the Horizontal Derivative of the integrated data set represents a first step for the interpretation of the maps in terms of geological structures of the whole Phlegrean volcanic district.
\end{abstract}

Key words aeromagnetic survey - Phlegrean Fields wavelet analysis

\section{Introduction}

The areas of Parete and Villa Literno, located north of the Phlegrean Fields (Naples, Italy) are characterized by the presence of intense magnetic anomalies with wavelength of tens of $\mathrm{km}$ (fig. 1) and by a remarkable thickness of volcanic rocks (about $1.5 \mathrm{~km}$ of basaltic and andesitic lavas were found in the Parete 2 Well), as observed in geothermal well data (Barbieri

Mailing address: Dr. Valeria Paoletti, Dipartimento di Scienze della Terra, Università degli Studi di Napoli «Federico II», Largo S. Marcellino, 80138 Napoli, Italy; e-mail:paoletti@unina.it et al., 1976). Despite the scientific and economic interest of this area, the aeromagnetic data previously available were only those shown in fig. 1 and surveyed in the 70s and 80s by Agip at a regional scale (Agip, 1981) which did not allow well resolved interpretation models. A more detailed aeromagnetic map of the area of the Phlegrean Fields was made by Agip in 1985, but limited to the area of the Gulf of Pozzuoli. A new aeromagnetic survey was therefore performed in October 2001, following a preliminary survey carried out in 1999 by our research group (fig. 1).

The Phlegrean Fields is an area of active volcanism located west of the town of Naples and characterized by a number of small volcanoes. Geologically there are mainly pyroclastic rocks that range in composition from trachybasalts to phonolitic alkali-trachytes (e.g., Rosi and Sbrana, 1987a). Some lava domes and 


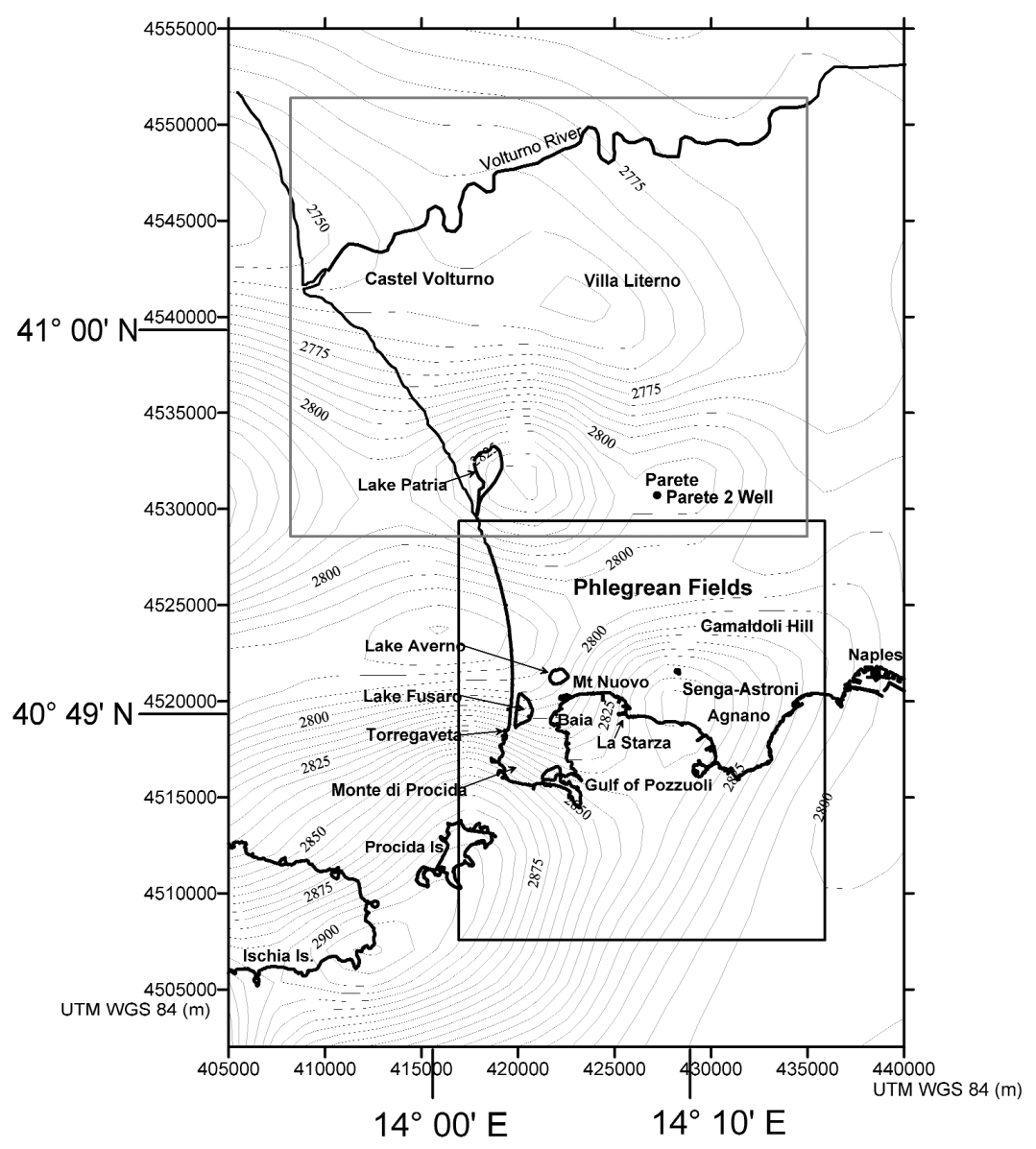

Fig. 1. The regional aeromagnetic map of the Phlegrean area measured by Agip (1981). The black rectangle shows the area surveyed by Agip in 1985 at a high resolution, while the grey rectangle shows the area surveyed in the new surveys of 1999 and 2001.

flows are present, and are mainly related to the early stages of activity (Upper Pleistocene). The most ancient volcanic products emerging in the Phlegrean Fields are about 50000 years old and are formed mainly of pyroclastic deposits and residues of lava domes. The structural pattern of the Phlegrean Fields results from the superimposition of two caldera collapses related to the Campanian Ignimbrite (CI) (36000 years old) and the Neapolitan Yellow Tuff (NYT) (12000 years old) eruptions (Orsi et al., 1996). In the last 12000 years a general subsidence in the Phlegrean Fields took place. In the last 5000 years the major tectonic event was a localized uplift inside the caldera, in the area of the town of Pozzuoli (e.g., Orsi et al., 1996). The expression of this uplift is the $3 \mathrm{~km}$ long marine terrace of $\mathrm{La}$ Starza, a fossil marine cliff running parallel to the coastline. This uplift was interpreted as the effect of the arrival of new magma into a shallow reservoir just before the onset of the last period of activity of Phlegrean Fields, started about 4500 years (Orsi et al., 1996). The last 
eruption, which occurred in 1538 in the Western Phlegrean Fields after a quiescence period, determined the formation of the tuff cone of Monte Nuovo. In the last 2000 years the Phlegrean Fields have been characterized by an intense hydrothermal activity and by a slow and continuous subsidence. The subsidence was interrupted only by some uplift phases, like the one before the Monte Nuovo eruption and the bradyseismic crises of 1969-1972 and of 19821984, which caused a total maximum uplift of about $3.3 \mathrm{~m}$ in the central area of the Phlegrean Caldera (Civetta, 1996). These uplifts have been accompanied by intense seismic activity with epicenters localized in the city and bay of Pozzuoli and by persistent fumarolic activity. From the end of 1988 the Phlegrean Fields Caldera has been subjected to subsidence interrupted only by a short uplift between 1988 and 1989, which was again accompanied by an increase of the fumarolic activity.

Because of its volcanic history and its numerous fumaroles and hot springs, the Phlegrean Fields-Ischia area is of particular geothermal interest. Several boreholes have been drilled in the Phlegrean Fields first by SAFEN (Società Anonima Forze Endogene Napoletane) during the 40s and the 50s and then, during the 70s and 80s, by ENEL and Agip (1987) in an extensive area around the Gulf of Pozzuoli. The area is characterized by variable and consistently high temperature gradients. A temperature of about $200{ }^{\circ} \mathrm{C}$ was measured at a depth of about $500 \mathrm{~m}$ in the Baia area (see fig. 1). The $200^{\circ} \mathrm{C}$ isotherm deepens towards the Fusaro and Averno Lakes, reaching $1 \mathrm{~km}$ depth at Agnano, where a maximum temperature of $300^{\circ} \mathrm{C}$ was measured at a depth of $1842 \mathrm{~m}$ (Agip, 1987).

Detailed studies of the gravity and magnetic fields were carried out in the Campanian Plain and, in particular, in the Phlegrean area. A detailed gravity survey of the Campanian Plain was presented by Cassano and La Torre (1987). The main features of the Bouguer anomaly map are: the presence of intense maxima corresponding to the carbonate cliffs bordering the Plain; a wide minimum area broken up by the highs of Parete area and Vesuvius dividing it into three smaller areas, Volturno (see fig. 1), Acerra and
Pompei (these latter are west and south of the surveyed area). These were interpreted as areas undergoing the greatest tectonic foundering. Finally, a clear circular gravity low is present in the Phlegrean area (Florio et al., 1999). The gravity high near Parete was interpreted as due to a volcanic structure (Baldi et al., 1976; Aprile and Ortolani, 1979) or as a buried carbonate horst with magmatic intrusions along its bordering faults as interpreted on the basis of the local magnetic signature appearing on a land based magnetic profile (Carrara et al., 1973). Rapolla et al. (1989) interpreted the gravity low in the Acerra area with two alternative models. The first involves a tectonic upper crust collapse with the formation of a basinal structure; the second is characterized by a low density magmatic body at depth, between about 9 and $12 \mathrm{~km}$.

The reduced to the pole aeromagnetic map measured by Agip in the Gulf of Pozzuoli area in 1985 (Florio et al., 1999) is characterized by three major positive anomalies on the SengaAstroni area, the Camaldoli Hill and Torregaveta, while a curved belt of negative anomalies, coincident with the belt of positive gravity anomalies, is present in the NW sector of Phlegrean Fields.

An accurate inspection of gravity and magnetic lineaments detected by means of boundary analysis techniques (Florio et al., 1999) has proved useful in delineating the structural settings of Campanian Plain and Phlegrean Fields, leading to a hypothesis of a strong structural control of the border faults of the Acerra depression on the volcanism in the Neapolitan area. The main structures recognized by the authors can be interpreted as reflecting the geometry of the collapsed caldera, indicating, for the Phlegrean Caldera, an area considerably less extended than that based on previous geologically-defined models (Rosi et al., 1983; Rosi and Sbrana, 1987b), and suggesting a possible origin of the caldera connected to the NYT eruption, as already inferred by some other authors (Lirer et al., 1987). Finally, the recent seismicity appears strongly correlated with the main density and magnetic boundaries inside the caldera (Florio et al., 1999) suggesting that these structures are very young. 

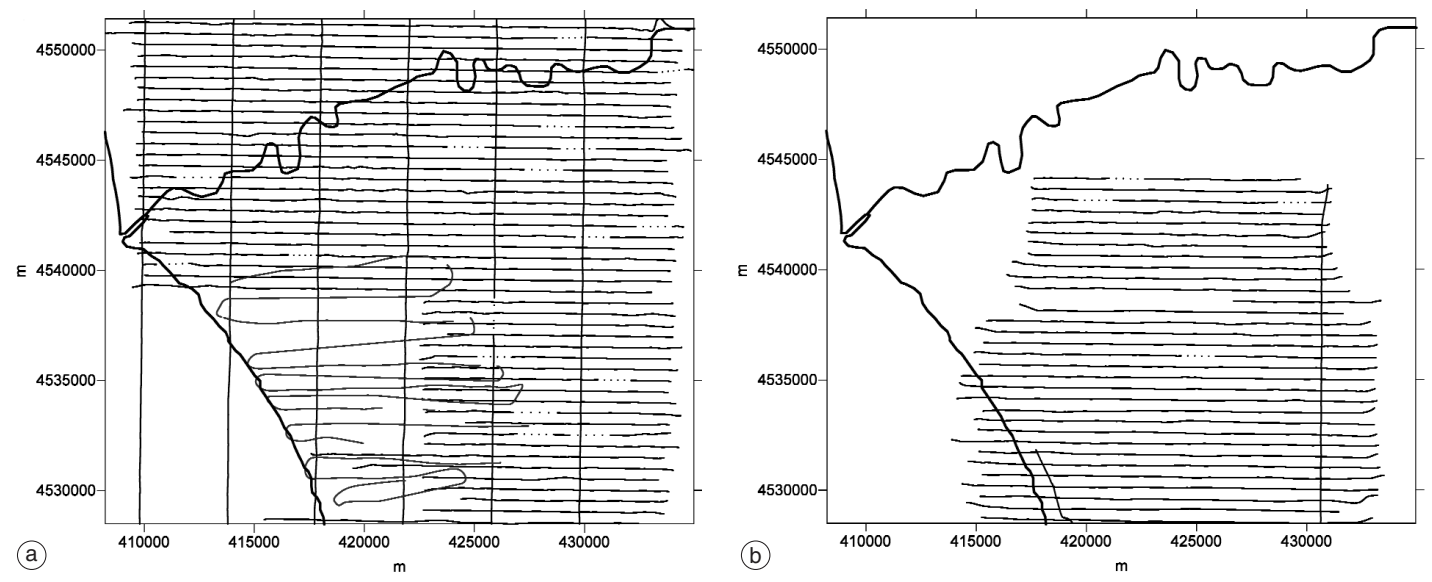

Fig. 2a,b. Flight lines flown in the new survey. a) Flight lines relative to the first level (70 $\mathrm{m}$ above the ground surface); the lines in grey are relative to the preliminary survey carried out in 1999, while the black fly lines are relative to the survey of 2001. b) Flight lines relative to the second level (400 $\mathrm{m}$ above the ground surface).

The new detailed aeromagnetic survey in the Northern Phlegrean area was aimed at providing more information and insights into the structural and volcanological characteristics of the Northern Phlegrean Fields and, by the integration of the new and the previous data sets, at bringing new elements about the whole Phlegrean Volcanic area. Gridded, composite data sets allow in fact a more complete view of patterns and trends that individual data sets may not provide.

\section{The new aeromagnetic survey in the Northern Phlegrean area}

\subsection{Technical and logistical characteristics of the survey}

The new detailed aeromagnetic survey was carried out in 1999 and 2001 at two different flight altitudes, respectively, $70 \mathrm{~m}$ and $400 \mathrm{~m}$ above the ground surface. This was done for three reasons: a) studying how the cultural effects interferes at different altitudes; b) testing the performance of upward continued filtered data versus measured data at the same level; c) multilevel inversion (Fedi and Rapolla, 1999). Points b) and c) will not be discussed in this paper.

At both levels the flight lines (having W-E azimuth) were spaced $400 \mathrm{~m}$ apart, while the tielines (having N-S azimuth) were about $2.5 \mathrm{~km}$ apart (fig. 2a,b). This allowed anomalies of sources at various depth and dimensions to be shown with different resolutions. The flight lines relative to the preliminary survey carried out in 1999 (in grey in fig. 2a) were characterized by a wider spacing than those flown during the survey performed in 2001 (in black in fig. 2a).

The instrumentation used for this survey consisted of ground and flight sections. The ground section was a magnetometer used to monitor the external field activity during flights and a GPS reference station, used for the differential correction of satellite data. The flight section contained: i) a cesium magnetometer having a precision of $0.01 \mathrm{nT}$, which was contained in a «bird» flown 30 m below the helicopter; ii) a GPS sensor for the horizontal positioning of the helicopter, having a precision of $\pm 1 \mathrm{~m}$ after the differential correction; iii) a laser-altimeter for the vertical positioning of the helicopter, and iv) a computer for data acquisition. 


\subsection{Data pre-processing}

The magnetic data pre-processing allowed several data corrections and included the following steps: i) removal of spikes and gaps in the data; ii) flight path check and re-positioning, which consisted in removal of wrong coordinates and double records, differential correction of the GPS data and check of the flight altitude; iii) earth's magnetic field diurnal variation corrections, which were performed using the local base station and, for one day, the data from the magnetic Observatory of L'Aquila, Italy; iv) removal of the IGRF (International Geomagnetic Reference Field), performed using the ITalian Geomagnetic Reference Field (ITGRF) updated for 2000 (De Santis et al., 2001); v) statistical leveling, consisting in a minimization of the differences between the field values measured at the crossing points between flight lines and tie lines; vi) decorrugation, a directional filtering to allow the removal of the directional anomalies still present along the flight lines.

\section{The new aeromagnetic map of the Northern Phlegrean area}

The aeromagnetic fields measured at the two levels are shown in fig. 3a,b. Data sets were gridded to an interval of $400 \mathrm{~m}$. The aeromagnetic map relative to the first level (fig. 3a), obtained by merging the data with those of the previous survey of 1999, flown at the same distance from the ground, is characterized by two anomalies of interest in the south sector of the surveyed area (of amplitude of about 300-350 nT) and by intense linear anomalies due to the presence of railway lines. High-frequency anomalies occur in all of the surveyed area, produced by cultural sources in a densely inhabited region. This cultural noise is strongly attenuated but still partially visible in the second level $(400 \mathrm{~m}$ above the ground surface), where anomalies appear much more smoothed (fig. 3b).

The presence of these intense anomalies may alter and/or mask the geology-related part of the measured signal and, therefore, in order to perform a reliable interpretation of these data it is necessary to filter them. To this end a powerful method based on discrete wavelet transform was used (Fedi and Quarta, 1998), the main advantage of this method being that the analysis can be carried out with mathematical models characterized by both a frequency and a space resolution. This is important, especially when compared with Fourier methods, which have good frequency resolution, but no space resolution. A specific space-scale wavelet analysis, called multi-resolution analysis, al-
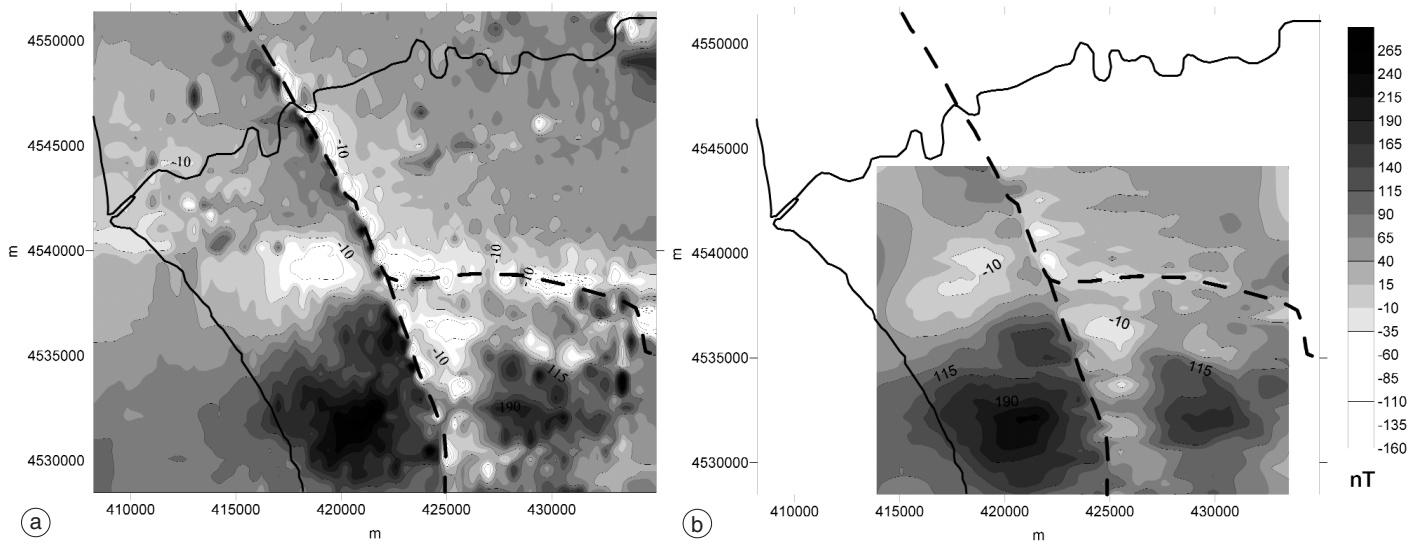

Fig. 3a,b. Aeromagnetic field measured in the new survey. The dashed lines show the railway line. a) Field measured at $70 \mathrm{~m}$ above the ground surface. b) Field measured at $400 \mathrm{~m}$ above the ground surface. 
lowed decomposing the signal with respect to a wide range of scales. The most appropriate basis was chosen by requiring the maximum of compactness for the multiresolution analysis. Since such analysis is not shift-invariant, the same criterion was applied to choose the best signal shift too. In the case of potential fields good bases are the interpolating and the triangular, which are both biorthogonal (Fedi and Quarta, 1998). In fact, their shape is rather consistent with the shape of simple anomalies. The used algorithm automatically identifies the wavelet coefficients by simply specifying the sub-area coordinates, this one having any desired shape. The excellent space-scale localization properties of the wavelet bases allowed a very sharp and space-localized filtering, leaving the field in adjacent areas unchanged.

\section{Analysis of the new integrated aeromagnetic map of the Phlegrean Fields volcanic area}

We performed the filtering of the new aeromagnetic data set only on the first one of the two levels, placed at about $70 \mathrm{~m}$ above the ground surface. The space-localized filtering of the anomalies related to the railway line was performed specifying a closed region straddling the railway and considering the two smallest scales. A further filtering of the high-frequency anomalies occurring all over the surveyed area was performed again by the discrete wavelet transform considering only the finest scale. The anomalies removed by these filtering processes are shown in fig. 4, whereas the aeromagnetic field obtained after the whole wavelet filtering is shown in fig. 5. The filtered map is mainly characterized by the presence of two separated anomalies of amplitude of about 250-350 nT connected to a positive contrast of magnetization in the southern sector of the surveyed area (fig. 5).

In order to obtain the new aeromagnetic map of the whole Phlegrean volcanic district we integrated the new data set of fig. 5 with the existing Agip aeromagnetic map of the Phlegrean Fields measured by Agip in 1985 in the Gulf of Pozzuoli area along flight lines about $250 \mathrm{~m}$ apart and at an altitude of $700 \mathrm{~m}$ a.s.1.

As shown in fig. 1, the areas covered by the two surveys are partially overlapping. To obtain a single aeromagnetic map for the whole Phlegrean Fields we had to continue the new data set upward to the altitude of $700 \mathrm{~m}$, since the topography rises up to almost $500 \mathrm{~m}$ at the volcanic hill of Camaldoli. The integration of the

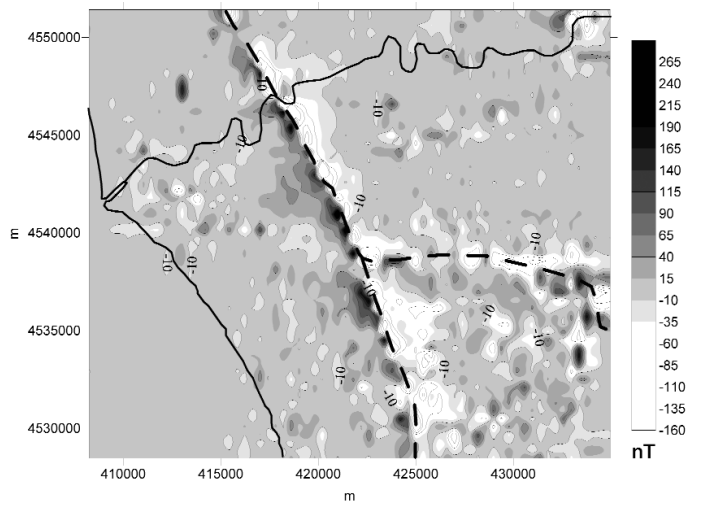

Fig. 4. Anomalies removed in the filtering and denoising processes at $70 \mathrm{~m}$ above the ground surface. The dashed line shows the railway line.

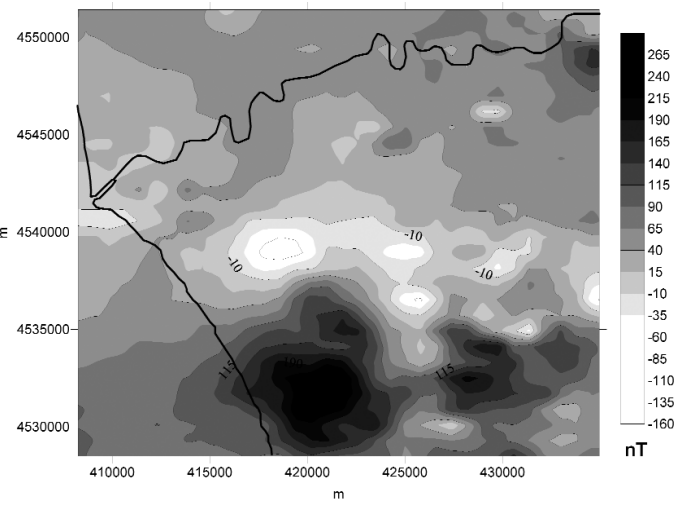

Fig. 5. Aeromagnetic field at $70 \mathrm{~m}$ above the ground surface after the filtering and denosing processes. 
two different data sets was performed through the following procedures:

i) Upward continuation of the data set of fig. 5 from an arbitrary surface to $700 \mathrm{~m}$ a.s.l., same altitude as the Agip data set (Bhattacharyya and Chan, 1977).

ii) Gridding of the Agip data set to an interval consistent with those of the data set of fig. $5(400 \mathrm{~m})$.

iii) Filtering of the highest-frequency anomalies occurring in area surveyed by Agip; this denoising was performed again by the discrete wavelet transform using the same parameters which were utilized for filtering the high-frequency anomalies occurring all over the area surveyed in 1999-2001 (see Section 3).

iv) Determination of the mismatch between data values of the two data sets across the boundary of the different surveyed areas; this mismatch can be explained by changes in level, gradient and curvature of the fields in the two data sets around the boundary, due to inaccuracy in the compilation of aeromagnetic data for contouring and to removal of inaccurate International Geomagnetic Reference Field (IGRF) around the edges of an area (Bhattacharyya et al., 1979).

v) Removal of the mismatch between the two data sets. As observed by Bhattacharyya et al. (1979), the difference in values of data sets in the overlapping parts of neighboring areas is a function of spatial coordinates, and within the area of overlap this mismatch may be represented by a quadratic surface matching the fields on both sides of the boundary. In the specific case presented here, we used a polynomial surface of zero order.

vi) Merging of the two separate grids in one grid. The gridding of the data set obtained from the integration of the two data sets was performed using a bilinear interpolation.

The map obtained of the aeromagnetic field of the whole Phlegrean area at $700 \mathrm{~m}$ a.s.l. (fig. 6 ) is characterized by the presence of large anomalies both in the Northern and Southern Phlegrean Fields. In particular, in the northern sector of Phlegrean Fields the magnetic field is characterized by two anomalies in the areas of Patria Lake and Parete with amplitudes of about $220 \mathrm{nT}$ and $120 \mathrm{nT}$, respectively, while in the area of the Gulf of Pozzuoli there are three major anomalies corresponding to Torregaveta, the Camaldoli Hill and Senga-Astroni, connected to a positive contrast of magnetization and whose amplitudes are 260 nT, $200 \mathrm{nT}$ and 110 $\mathrm{nT}$, respectively.

In order to locate the position of the magnetic sources of the anomalies of the area we computed a pole reduced map (fig. 7), using for the induced and total magnetization vectors the direction of the present inducing field in the area (inclination $=60^{\circ}$; declination $=0^{\circ}$ ).

However, the direction of total magnetization vector in an area may be not constant and thus the reduced to the pole map may exhibit some badly distorted anomalies. Some authors (Nabighian, 1984; Roest et al., 1992) showed the amplitude of Analytic Signal to have useful properties, being less sensitive to the direction of the magnetization vector, and therefore helping to better correlate the magnetic anomalies above their sources. The Analytic Signal is formed through a combination of the horizontal and vertical gradients of a magnetic anomaly, its amplitude $A$ being given by the vectorial sum of the three derivatives of the potential field $M$

$$
|A(x, y)|=\sqrt{\left(\frac{\partial M}{\partial x}\right)^{2}+\left(\frac{\partial M}{\partial y}\right)^{2}+\left(\frac{\partial M}{\partial z}\right)^{2}} .
$$

In cases of sufficiently high resolution and wide sources, the Analytic Signal presents its maxima directly over vertical and abrupt magnetization contrasts, otherwise it has a single bell shape over the source. However, since the shape of the Analytic Signal is slightly dependent on the direction of magnetization and, more specifically, on the value of the magnetic inclination, the maximum of this function is not always located directly over a dipolar source (Agarwal and Shaw, 1996; Lin-ping et al., 1997; Lin-ping and Zhi-ning, 1998); Salem et al. (2002) showed that these shifts are also functions of the source-to-observation distance.

To locate the lateral boundaries limiting the magnetic sources we used also the location of maxima of the Horizontal Derivative of the pole reduced magnetic field. Cordell and 

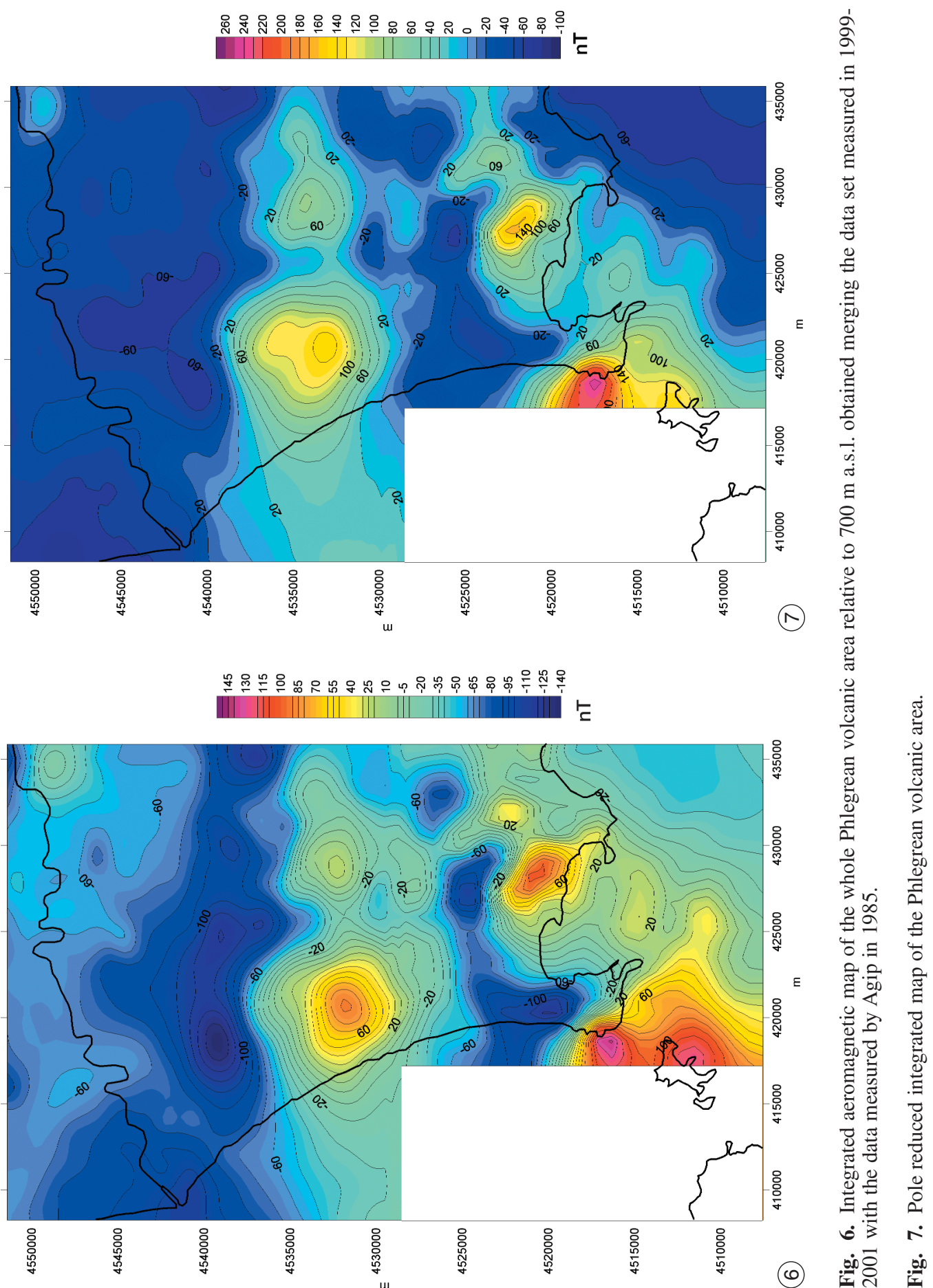


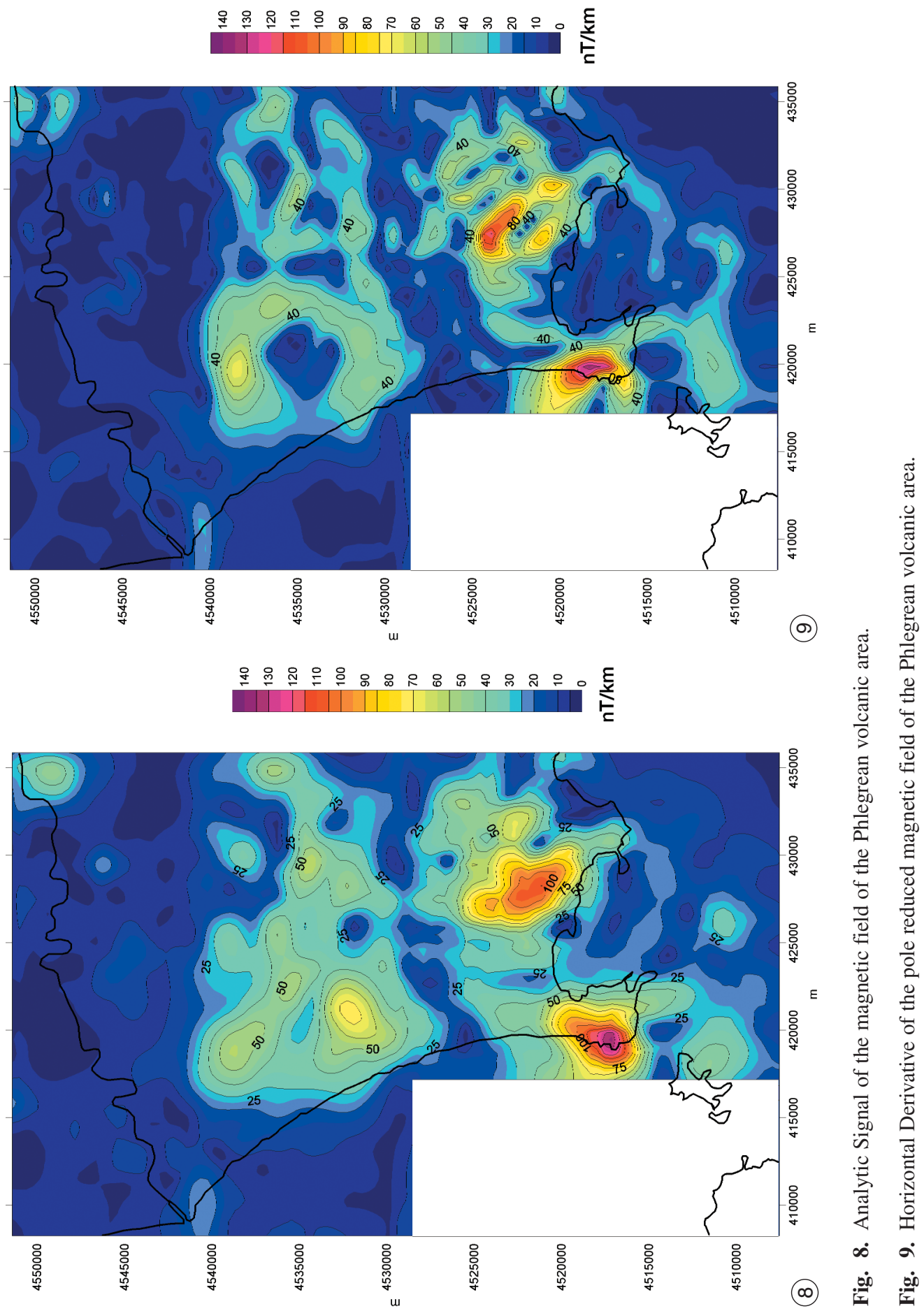


Grauch (1985) showed indeed that the maxima of the Horizontal Derivative of gravity or pole reduced magnetic anomalies are located above changes of density or magnetization. However, since the horizontal-gradient method assumes that the boundaries can be approximated as single, near-vertical, sharp boundaries, when the boundaries are not represented by a vertical contact or when several boundaries are close together, the location of the gradient maximum can be offset from the boundary (Grauch and Cordell, 1987). The amount of this offset is determined by the depth of the top edge of the boundary below the observation and by the dip of the boundary. An offset in the presence of dipping contacts is also common to the Analytic Signal method. In this paper both the magnitude of the Analytic Signal and of the Horizontal Derivative will be analysed, applying the first one to the measured aeromagnetic field and the latter to its reduced to the pole version.

The map of the Analytic Signal of the magnetic field of the area (fig. 8) does not always

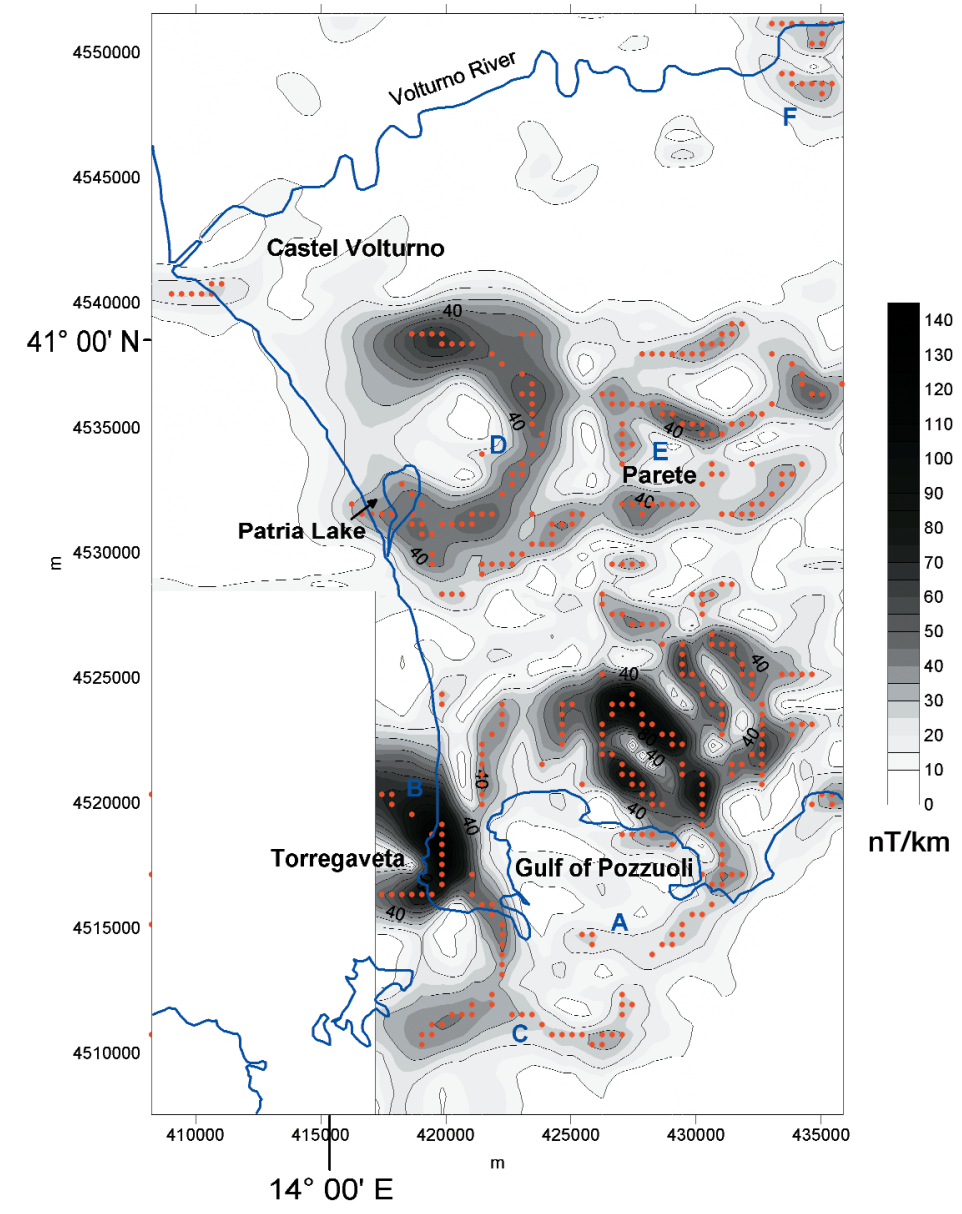

Fig. 10. Map of the Horizontal Derivative plotted in a gray scale. The main maxima of the function are indicated by red dots. 
present its maxima over the magnetization contrasts. In fact, the Analytic Signal often has a single bell-shaped anomaly over the approximate position of the sources, as in the case of the anomalies of Torregaveta and Senga-Astroni and of the isolated sources in the northern part of the surveyed area (along and south of the Volturno River). However, this simplified image of the position of the source bodies gives very valuable results in those parts of the map where there is a strong interference between nearby sources. This is the case of the Agnano-Astroni area, where in the Analytic Signal map a number of distinct magnetized bodies are clearly identified by single bellshaped anomalies. Thus this map can be used, together with that of the original aeromagnetic field, as a guide for interpreting the more informative Horizontal Derivative map. The map of the Horizontal Derivative of the pole reduced magnetic field of the area (fig. 9) allows a good representation of the pattern of the lateral boundaries of the above sources and also suggests the presence of linear trends.

\section{Discussion and conclusions}

The main structures suggested by the above analysis are shown in fig. 10. Here the Horizontal Derivative is plotted in a gray scale to highlight the main maxima of the HD function by red dots. The location of the maxima of the horizontal gradients of the magnetic data, interpreted also in light of the analysis of the Analytic Signal, is a useful method for guiding the interpretation of patterns and features that may be otherwise difficult to detect in the original data (Blakely and Simpson, 1986). The boundaries shown correspond to the faults, contacts and magnetic lineaments of the area, and this allows the main structural features characterizing the Phlegrean Fields in the Gulf of Pozzuoli to be well illustrated; in particular the borders of the Yellow Tuff Caldera (A in fig. 10) and of the Torregaveta anomaly (B in fig. 10) are clearly shown. It should also be noticed that just south of the caldera a small arcuate structure appears ( $\mathrm{C}$ in fig. 10), which may represent a volcanic body, according also to the indications coming from the Analytic Signal map that allows individuating a single isolated body in that position.

In the central part of the investigated area, a number of structures already highlighted in the Analytic Signal map are shown. These features seem aligned along an east-west trend that may be viewed as an eastward prolongation of the well known Tyrrhenian $41^{\circ} \mathrm{N}$ parallel magnetic lineament, an E-W elongated magnetic anomaly zone separating the Northern Tyrrhenian Domain from the Southern Tyrrhenian Domain, which appears to be correlated to the evolution of the Tyrrhenian Sea (Lavecchia, 1988; Spadini and Wezel, 1994; Ferranti et al., 1996). The main structure in this area is the so-called «Patria Lake» anomaly ( $\mathrm{D}$ in fig. 10 ); this body seems to have a fairly circular shape, with a diameter of about $10 \mathrm{~km}$. East of this anomaly, along the same alignment, a more complex pattern appears, formed by the Parete anomalies and by several others (E in fig. 10). Finally, even though north of this E-W lineament the area appears magnetically quiet, in the NE corner of the map an isolated and interesting anomaly appears in correspondence with the Volturno River ( $F$ in fig. 10) showing, together with other very small anomalies south of this river, the presence of a diffused volcanic activity all over the Campanian Plain. Such a suggestion of the presence of buried magnetized structures in the northern section of the map is very interesting, also in view of the lack of any surface geological evidence.

\section{Acknowledgements}

The authors acknowledge the support of the GNV-OV grants to A. Rapolla and to R. Pece (Programma Quadro 2000-2002). The authors also acknowledge I. Giori (Eni-Agip) for the availability of Phlegrean aeromagnetic data set from 1985 and CIRAM, University of Naples, for providing the data about the location of the railway line.

Finally the authors are grateful to an anonymous reviewer and to D. Ravat and I. Nicolosi for their valuable suggestions. 


\section{REFERENCES}

Agarwal, B.N.P and R.K. Shaw (1996): Comment on: «An analytic signal approach to the interpretation of total field magnetic anomalies» by Shuang Qin, Geophys. Prospect., 44, 911-914.

AgIP (1981): Carta Aeromagnetica d'Italia (Scala 1:500000), Att. Min., Direz. Espl. Idrocarburi, S. Donato Milanese.

AGIP (1987): Geologia e Geofisica del Sistema Geotermico dei Campi Flegrei, DES, SERG-MESG, S. Donato Milanese.

APRILE, F. and F. ORTOLANI (1979): Sulla struttura profonda della Piana Campana, Boll. Soc. Nat. Napoli, 88

Baldi, P., G.M. Cameli, B. D’Argenio, A. Oliveri Del Castillo, T. Pescatore, L. Puxeddu, A. Rossi and B. ToRo (1976): Geothermal research in Western Campania (Southern Italy): a revised interpretation of the Qualiano-Parete structure, in Proc. Int. Congr. on Thermal Waters, Geoth. Energy and Volcanism of the Mediterranean Area, Athens.

Barbieri, M., P. Di Girolamo, E. Locardi, G. LOMbardi, D. STANZione and M. NiCOLETTI (1976): Geothermal research in Western Campania (Italy): stratigraphy of the Parete exploratory well and new data on the volcanic sequence, in Proc. Int. Congr. on Thermal Waters, Geoth. Energy and Volcanism of the Mediterranean Area, Athens.

BHATTACHARYYA, B.K. and K.C. CHAN (1977): Reduction of magnetic and gravity data on an arbitrary surface acquired in a region of high topographic relief, Geophysics, 42, 1411-1430.

BhatTaCharyya, B.K., R.E. SweEney and R.H. Godson (1979): Integration of aeromagnetic data acquired at different times with varying elevations and line spacings, Geophysics, 44, 742-752.

Blakely, R.J. and R.W. Simpson (1986): Approximating edges of source bodies from magnetic or gravity anomalies, Geophysics, 51, 1494-1498.

Carrara, E., F. Iacobucci, E. Pinna and A. Rapolla (1973): Gravity and magnetic survey of the Campanian volcanic area, Southern Italy, Boll. Geofis. Teor. Appl., XV (57), 39-51.

CAssano, E. and P. LA Torre (1987): Geophysics, in Phlegrean Fields, edited by M. Rosi and A. SBRANA, CNR Ouad. Ric. Sci., 114, 103-133.

CivetTA, L. (1996): Vesuvius and Phlegrean Fields: their activity and the problem of volcanic surveillance, in The Safe City, edited by A. NAZZARO and A. RAPOLLA, 39-60.

CORDELL, L. and V.J.S. GRAUCH (1985): Mapping basement magnetization zones from aeromagnetic data in the San Juan basin, New Mexico, in The Utility of Regional Gravity and Magnetic Anomaly Maps, edited by W.J. HINZE (Society of Exploration Geophysics), 181-197.

De Santis, A., L. Gaya-Piqué, G. Dominici and J.M. ToRTA (2001): Italian Geomagnetic Field ITGRF: update for 2000 and secular variation model up to 2005, in II International Workshop on Geo-Electro-Magnetism, 26-28 September 2001, Lerici, La Spezia.

FEDI, M. and T. QUARTA (1998): Wavelet analysis for the regional-residual and local separation of potential field anomalies, Geophys. Prospect., 46, 507-525.

FEDI, M. and A. RAPOLLA (1999): 3D inversion of gravity and magnetic data with depth resolution, Geophysics, 64, 452-460.

FERRANTI, L., J.S. Oldow and M. SACCHI (1996): Pre-Quaternary orogen-parallel extension in the Southern Apennine belt, Italy, Tectonophysics, 260, 247-325.

Florio, G., M. Fedi, F. Cella and A. Rapolla (1999): The Campanian Plain and Phlegrean Fields: structural setting from potential field data, J. Volcanol. Geotherm. Res., 91, 361-379.

Grauch, V.J.S. and L. CORDELl (1987): Limitations of determining density or magnetic boundaries from the horizontal gradient of gravity or pseudogravity data, Geophysics, 52, 118-121.

LaVecchia, G. (1988): The Tyrrhenian-Apennines system: structural setting and seismo-tectogenesis, Tectonophysics, 147, 263-296.

LIN-PING, H. and G. ZHI-NING (1998): Discussion on «Magnetic interpretation using the $3 \mathrm{D}$ analytic signal» by W.R. Roest, J. Verhoef and M. Pilkington, Geophysics, 63, 667-670.

LiN-PING, H., G. ZHI-NING and Y. CHANG-LI (1997): Comment on: «An analytic signal approach to the interpretation of total field magnetic anomalies» by Shuang Qin, Geophys. Prospect., 45, 879-881.

LiRER, L., G. LuONGO and R. SCANDONE (1987): On the volcanological evolution of Campi Flegrei, EOS, Trans. Am. Geophys. Un., 68, 226-234.

NABIGHIAN, M. (1984): Toward a three-dimensional automatic interpretation of potential field data via generalized Hilbert transforms: fundamental relations, Geophysics, 49, 780-786.

Orsi, G., S. DE ViTA and M. DI Vito (1996): The restless resurgent Campi Flegrei nested caldera (Italy): constraints on its evolution and configuration, J. Volcanol. Geotherm. Res., 74, 179-214.

Rapolla, A., M. Fedi and M.G. Fiume (1989): Crustal structure of the Ischia-Phlegrean geothermal fields, near Naples, Italy, from gravity and aeromagnetic data, Geophys. J., 97, 409-419.

Roest, W.R., J. Verhoef and M. Pilkington (1992): Magnetic interpretation using the $3 \mathrm{D}$ analytic signal, Geophysics, 57, 116-125.

Rosi, M. and A. Sbrana (1987a): Petrography, in Phlegrean Fields, edited by M. Rosi and A. SBRANA, CNR Quad. Ric. Sci., 114 (9), 60-80.

Rosi, M. and A. Sbrana (1987b): Tectonics, in Phlegrean Fields, edited by M. M. Rosi and A. SBRANA, CNR Quad. Ric. Sci., 114 (9), 80-94.

Rosi, M., A. Sbrana and C. PrinciPe (1983): The Phlegrean Fields structural evolution, volcanic history and eruptive mechanisms, J. Volcanol. Geotherm. Res., 17, 273-288.

Salem, A., D. Ravat, T. JefrRey Gamey and K. UshiJima (2002): Analytic signal approach and its applicability in environmental investigations, J. Appl. Geophys., 49 231-244.

SPADINI, G. and F.C. WeZEL (1994): Structural evolution of the 41st parallel zone: Tyrrhenian Sea, Terra Nova, 6, 552-562.

(received September 15, 2003 accepted May 18, 2004) 